\title{
Trimethyltin-Induced Microglial Activation via NADPH Oxidase and MAPKs Pathway in BV-2 Microglial Cells
}

\author{
Da Jung Kim and Yong Sik Kim \\ Department of Pharmacology, Seoul National University College of Medicine, 103 Daehakno, Jongno-gu, \\ Seoul 110-799, Republic of Korea
}

Correspondence should be addressed to Yong Sik Kim; kimysu@snu.ac.kr

Received 22 April 2015; Revised 10 June 2015; Accepted 11 June 2015

Academic Editor: Ulrich Eisel

Copyright (C) 2015 D. J. Kim and Y. S. Kim. This is an open access article distributed under the Creative Commons Attribution License, which permits unrestricted use, distribution, and reproduction in any medium, provided the original work is properly cited.

\begin{abstract}
Trimethyltin (TMT) is known as a potent neurotoxicant that causes neuronal cell death and neuroinflammation, particularly in the hippocampus. Microglial activation is one of the prominent pathological features of TMT neurotoxicity. Nevertheless, it remains unclear how microglial activation occurs in TMT intoxication. In this study, we aimed to investigate the signaling pathways in TMT-induced microglial activation using BV-2 murine microglial cells. Our results revealed that TMT generates reactive oxygen species (ROS) and increases the expression of CD11b and nuclear factor- $\kappa \mathrm{B}-(\mathrm{NF}-\kappa \mathrm{B}-)$ mediated nitric oxide (NO) and tumor necrosis factor- (TNF-) $\alpha$ in BV-2 cells. We also observed that NF- $\kappa$ B activation was controlled by $\mathrm{p} 38$ and JNK phosphorylation. Moreover, TMT-induced ROS generation occurred via nicotinamide adenine dinucleotide phosphate (NADPH) oxidase in BV-2 cells. Interestingly, treatment with the NADPH oxidase inhibitor apocynin significantly suppressed p38 and JNK phosphorylation and NF- $\kappa$ B activation and ultimately the production of proinflammatory mediators upon TMT exposure. These findings indicate that NADPH oxidase-dependent ROS generation activated p38 and JNK mitogen-activated protein kinases (MAPKs), which then stimulated NF- $\kappa$ B to release proinflammatory mediators in the TMT-treated BV-2 cells.
\end{abstract}

\section{Introduction}

Organotin compounds, particularly di- and trialkyl tins, are used as stabilizers in polyvinyl chloride (PVC) and as biocides [1]. Poisoning accidents involving these compounds have been reported [2]. Trimethyltin (TMT) is known to be highly neurotoxic compared to other organotin compounds. Human exposure to TMT causes neuropathological symptoms, cognitive impairments, hyperactivity, aggressive behavior, and seizures $[1,3]$. These clinical symptoms are closely related to limbic system dysfunction in the brain [4]. In rodent models, TMT administration induces massive neuronal cell loss with glial reactivity in the brain and behavioral alternations that include cognitive impairments, hyperactivity, and tonic-clonic seizures [4-6]. However, the precise mechanism governing its neurotoxicity remains unclear. Thus far, the suggestions regarding TMT-induced neurotoxic mechanisms include calcium overload [4], excitotoxicity [7], mitochondrial dysfunction [6], oxidative stress [4, 6], and neuroinflammation $[5,8]$. Among these neurotoxic mechanisms, neuroinflammation has recently emerged as a key player because extensive glial activation and proinflammatory cytokine production are accompanied by neuronal death in many neurodegenerative disorders $[9,10]$.

In the central nervous system (CNS), microglia are the resident macrophage-like cells and play a large role in immune system [11]. Lipopolysaccharide (LPS) $[12,13]$ and various neurotoxins such as amyloid beta $(\mathrm{A} \beta)[13,14]$, 1-methyl-4-phenyl-1,2,3,6-tetrahydropyridine (MPTP) [15], and rotenone [16] can activate microglia to release cytotoxic factors, such as superoxide $\left(\mathrm{O}_{2}{ }^{-}\right)$, nitric oxide (NO), tumor necrosis factor- (TNF-) $\alpha$, and interleukin- (IL-) $1 \beta[15$, 17], factors that reliably trigger neuronal death $[15,18]$. The proinflammatory products from activated microglia are generally known to appear via mitogen-activated protein kinases 
(MAPKs) and the NF- $\kappa$ B pathway $[19,20]$. The association between neuroinflammation and microglial activation was elucidated by studies in Alzheimer's disease [9], Parkinson's disease [10], and multiple sclerosis [21].

The administration of TMT to rodents induces early, pronounced glial reactivity with neuronal death, and the enhancement of inflammatory factors including TNF- $\alpha$, IL$1 \beta$, IL-12, IL-23, and NO in the hippocampus $[5,6]$. Previously, it was reported that amoeboid microglia with elevated mRNA levels of proinflammatory factors, such as TNF- $\alpha$ and macrophage inflammatory protein- (MIP-) $1 \alpha$, were detected at an early time point after TMT treatment [22]. In the rat hippocampal slice culture [6] and mixed neuronal cultures [23], selective microglial changes prior to any sign of neuronal damage have been reported. Moreover, the microglial activation induced by TMT potentiates neuronal cell death in a coculture of neurons with microglia [24]. Similarly, it has also been reported that TMT can evoke microglial activation in cocultures of microglia with astrocytes $[25,26]$. These in vitro and in vivo studies indicate the importance of cell-to-cell interactions, particularly between microglia and neurons and between microglia and astrocytes in TMTinduced neuroinflammatory reactions $[4,5,24]$.

However, few studies have examined the underlying mechanism of direct activation in microglia by TMT. From this background, we aimed to evaluate whether TMT can induce the microglial activation and what kinds of signaling pathways are involved in this process using BV-2 microglial cells.

\section{Materials and Methods}

2.1. Reagents. Dulbecco's modified Eagle's medium (DMEM), phosphate-buffered saline (PBS), Hank's balanced salt solution (HBSS), fetal bovine serum (FBS), normal goat serum (NGS), and antibiotic-antimycotic were purchased from Gibco (Grand Island, NY, USA). Trimethyltin chloride, 2,7-dichlorofluorescin diacetate (DCFH-DA), 1-(4,5-dimethylthiazol-2-yl)-3,5-diphenylformazan (MTT), dimethyl sulfoxide (DMSO), bovine serum albumin (BSA), Tween-20, Hoechst 33258, SB203580, SP600125, apocynin, and BAY117082 were from Sigma-Aldrich (St. Louis, MO, USA). Rabbit antibodies against p-JNK, p-p38, p-ERK, p-I $\kappa \mathrm{B} \alpha, \mathrm{p} 38$, and $\mathrm{I} \kappa \mathrm{B} \alpha$ were purchased from Cell Signaling Technologies, Inc. (Beverly, MA, USA). Rabbit anti-JNK, ERK, and NF- $\kappa$ B p65 antibodies were from Santa Cruz Biotechnology (Santa, CA, USA). Mouse anti-inducible nitric oxide synthase (iNOS) was from BD Biosciences (Franklin Lakes, NJ, USA). Mouse antiactin was purchased from EMD Millipore (Billerica, MA, USA). Rat anti-CD11b was from AbD Serotec (Oxford, UK). The goat anti-mouse, -rabbit, and -rat IgG (HRP-conjugated) secondary antibodies were from Enzo Life Science (Farmingdale, NY, USA). All other chemicals were purchased from Sigma-Aldrich.

2.2. Cell Culture and Treatment. The murine microglial BV-2 cells (generated from primary microglia transfected with a v-raf/v-myc oncogene [27]) were a gift from Dr.
Sang-Kyu Ye (Seoul National University, Seoul, Korea). The cells were maintained at $36^{\circ} \mathrm{C}$ in a $5 \% \mathrm{CO}_{2}$ incubator with high-glucose DMEM supplemented with $10 \%(\mathrm{v} / \mathrm{v})$ heat-inactivated FBS, $1 \mathrm{x}$ antibiotic-antimycotic (consisting of 100 units $/ \mathrm{mL}$ penicillin, $100 \mu \mathrm{g} / \mathrm{mL}$ streptomycin, and $0.25 \mu \mathrm{g} / \mathrm{mL}$ amphotericin B), $2 \mathrm{mM}$ L-glutamine, and $1 \mathrm{mM}$ pyruvate at $\mathrm{pH}$ 7.4. At $80 \%$ confluence, the cells were harvested for subculture. The cells were seeded on a culture plate and incubated overnight in the culture medium containing $10 \%(\mathrm{v} / \mathrm{v})$ heat-inactivated FBS and antibiotics. For the western blot, ROS measurement and immunocytochemistry experiments, the media were then replaced with low-glucose DMEM without FBS and antibiotics and incubated for at least $4 \mathrm{hr}$ prior to various inhibitor treatments. For all of the inhibitors, including SB203580 (p38 MAPK inhibitor), SP600125 (JNK MAPK inhibitor), apocynin (nicotinamide adenine dinucleotide phosphate (NADPH) oxidase inhibitor) and BAY11-7082 ( $\mathrm{I} \kappa \mathrm{B} \alpha$ phosphorylation inhibitor), and the vehicle (0.1\% DMSO), the pretreatments lasted $1 \mathrm{hr}$, and TMT dissolved in saline was then added to the culture media for the indicated times.

2.3. Cell Viability: MTT. To determine the survival of the BV-2 cells upon TMT exposure, $1.5 \times 10^{4}$ cells were seeded in each well of a 96-well tissue culture plate (BD, Franklin Lakes, NJ, USA). After being left overnight, the cells were gently washed with PBS ( $\mathrm{pH} 7.4$ ) twice, and the medium was replaced with low-glucose DMEM medium with $1 \%(\mathrm{v} / \mathrm{v})$ FBS. Various concentrations of TMT were applied to the BV2 cells. After $24 \mathrm{hr}$ of incubation, the medium was removed, and the MTT solution (final concentration, $0.5 \mathrm{mg} / \mathrm{mL}$ ) was added. Following $3 \mathrm{hr}$ of incubation in a $\mathrm{CO}_{2}$ incubator at $36^{\circ} \mathrm{C}$, the MTT solution was aspirated, and $200 \mu \mathrm{L}$ of DMSO was added to each well. The absorbances were then read with a microplate reader (Tecan infinite M200 Pro, Tecan, San Francisco, USA) at $495 \mathrm{~nm}$. The absorbance of the control cells was set to $100 \%$.

2.4. Measurement of ROS. Intracellular ROS generation was measured with dichlorofluorescein diacetate (DCFH-DA) assays [28]. In $60 \mathrm{~mm}^{2}$ tissue culture dishes (BD, Franklin Lakes, NJ, USA), the treated cells at a density of $1 \times 10^{6}$ cells/mL were washed twice with prewarmed HBSS. Next, the cells were incubated with $15 \mu \mathrm{M}$ DCFH-DA at $36^{\circ} \mathrm{C}$ in a $\mathrm{CO}_{2}$ incubator for $30 \mathrm{~min}$. The cells were again washed twice. A Canto Flow Cytometer (BD Biosciences, CA, USA) was used to fluorescently quantify the cells (excitation at $488 \mathrm{~nm}$ and emission at $510 \mathrm{~nm}$ ). To provide statistical data, the value measured for the control was set to $100 \%$.

2.5. Western Blot Analysis. The treated cells were lysed with radioimmunoprecipitation assay (RIPA) buffer (Elpis Biotech, Daejeon, Korea) supplemented with protease and phosphatase inhibitor cocktails (Roche Diagnostics, Rotkreuz, Switzerland) and centrifuged at $14,000 \mathrm{~g}$ for $20 \mathrm{~min}$ at $4^{\circ} \mathrm{C}$. The supernatant was collected, and Bradford assays were used to measure the protein concentrations. Equal protein amounts $(20 \mu \mathrm{g})$ were separated by $10 \%$ 


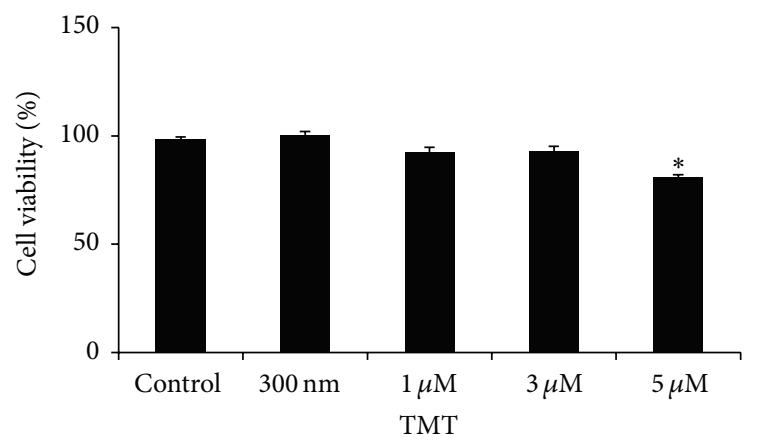

(a)

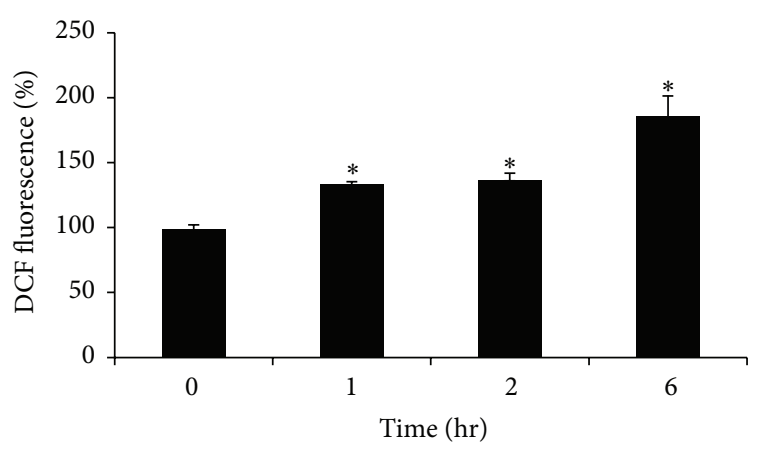

(b)

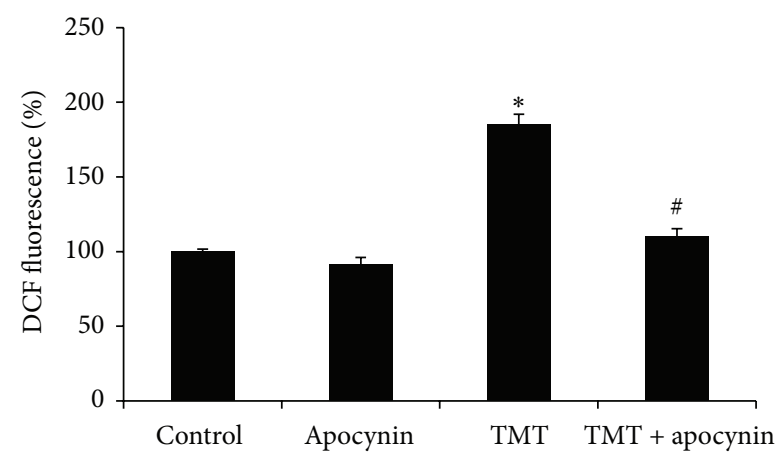

(c)

FIGURE 1: TMT-stimulated ROS generation in BV-2 cells. (a) For the cell viability test, the cells were treated with various concentrations of TMT $(300 \mathrm{nM}-5 \mu \mathrm{M})$ or vehicle (saline) for $24 \mathrm{hr}$; then MTT assay was performed to measure the cell viability. The value of each sample was normalized to control group. (b) For ROS measurement, $3 \mu \mathrm{M}$ TMT treated cells was incubated for the indicated periods of time (0-6 hr) and then stained with $15 \mu \mathrm{M}$ DCFH-DA for $30 \mathrm{~min}$. DCF-fluorescence of each sample was analyzed by the flow cytometry. The value measured at $0 \mathrm{hr}$ was set as $100 \%$. The data are represented as mean $\pm \operatorname{SEM}(n=4) .{ }^{*} P<0.05$ compared with control $(0 \mathrm{hr})$. (c) Cells were pretreated with $250 \mu \mathrm{M}$ apocynin prior to TMT treatment and then incubated for $6 \mathrm{hr}$. The data are represented as mean \pm SEM $(n=4) .{ }^{*} P<0.05$ compared with the value of control; ${ }^{*} P<0.05$ compared with the value of TMT.

(W/V) sodium dodecyl sulfate (SDS) polyacrylamide gel electrophoresis and then transferred onto $0.45 \mu \mathrm{m}$ pore size nitrocellulose membrane (Bio-Rad Laboratories, Hercules, CA, USA) for $1 \mathrm{hr}$ at $100 \mathrm{~V}$. After $1 \mathrm{hr}$ of blocking in $5 \%$ skim milk dissolved in $0.1 \%$ Tween-20 containing Tris-buffered saline (TBST) at $\mathrm{pH} 7.4$ for $1 \mathrm{hr}$ at room temperature, the membranes were incubated overnight at $4^{\circ} \mathrm{C}$ with primary antibodies against p-p38 $(1: 1000), \mathrm{p}$-JNK $(1: 1000)$, p-ERK (1:2000), p-I $\kappa \mathrm{B} \alpha$ (1:2000), p38 (1:2000), JNK (1:2000), ERK (1:2000), I $\kappa \mathrm{B} \alpha(1: 2000)$, iNOS $(1: 1000)$, and actin (1:2000). After washing with TBST three times for $10 \mathrm{~min}$ each, the membrane was incubated with goat anti-rabbit IgG-horseradish peroxidase (HRP) or anti-mouse IgG-HRP for $1 \mathrm{hr}$ and then rinsed three times with TBST. The blot was immunolabeled with enhanced chemiluminescence HRP substrate (Thermo Fisher Scientific Inc., Rockford, IL, USA), and a ChemiDoc XRS plus (Bio-Rad Laboratories, Hercules, CA, USA) was used to analyze the immunoblot. Actin was used as the loading control for the total protein.
2.6. Immunocytochemistry. To confirm the NF- $\kappa \mathrm{B}$ activation induced by TMT, the translocation of the NF- $\kappa \mathrm{B}$ p 65 subunit was observed via an immunocytochemistry method. Additionally, CD11b immunofluorescence was detected to examine the differences in expression between the different groups. CD11b is a cell surface molecule of microglia that is increased in the activated microglia and has been widely used as a marker in microglial activation [12, 18]. Briefly, $1.5 \times 10^{4}$ cells were seeded on poly-L-lysine-coated glass coverslips. After $12 \mathrm{hr}$ of TMT treatment, fixation with $4 \%$ paraformaldehyde was performed at room temperature for $15 \mathrm{~min}$. The coverslips were washed three times with PBS and blocked with PBS containing 3\% BSA, 0.3\% Triton X-100, and $10 \%$ NGS for $1 \mathrm{hr}$. Next, the cells were stained overnight with the following primary antibodies: rabbit polyclonal NF$\kappa$ B p65 (1:100) (Santa Cruz) or rat polyclonal CD11b (1:100) (AbD Serotec). Following three washes with PBS, the coverslips were incubated with fluorescein isothiocyanate- (FITC-) conjugated goat anti-rabbit or donkey anti-rat IgG antibody $(1: 200)$ for $1 \mathrm{hr}$. Hoechst 33258 was added to the slides $15 \mathrm{~min}$ 
prior to finishing the incubation with the secondary antibody. After three additional rinses, the coverslips were placed on the glass slides with an antifading mounting medium (Invitrogen, Carlsbad, CA, USA). Immunofluorescence images were obtained from a fluorescence microscope (Axioskop 40; Carl Zeiss, Jena, Germany) at 400x magnification.

2.7. Measurement of NO and TNF- $\alpha$ Release in the Culture Medium. In a 24-well tissue culture plate (Thermo Fisher Scientific Inc.), $2.5 \times 10^{4}$ cells were treated with TMT in low-glucose DMEM with $1 \%$ (v/v) FBS for $24 \mathrm{hr}$. Then, the medium was transferred and centrifuged at $500 \mathrm{~g}$ for $5 \mathrm{~min}$ at $4^{\circ} \mathrm{C}$. The supernatant fraction was collected for use in the measurements of NO and TNF- $\alpha$. For the NO measurements, a general protocol that has been described previously was followed [29]. Briefly, $90 \mu \mathrm{L}$ of each sample and $10 \mu \mathrm{L}$ of Griess reagent (containing 0.1\% N-[1-naphthyl] ethylenediamine dihydrochloride in $5 \% \mathrm{H}_{3} \mathrm{PO}_{4}$ with $1 \%$ of sulfanilic acid) were placed in 96-well tissue culture plate (BD Biosciences). For the standard values, different concentrations of sodium nitrite solution and Griess reagent were placed into the plate. The plate was then gently shaken for $30 \mathrm{~min}$. Absorbance was read in a microplate reader at $540 \mathrm{~nm}$. The nitrite concentration of each sample was calculated from the standard curve. To measure the amount of released TNF- $\alpha$, a TNF- $\alpha$ enzyme-linked immunosorbent assay (ELISA) kit was obtained from Abcam (Cambridge, UK). Each dilution of the standard and each sample were placed in the plate, and subsequent experiments were performed according to the manufacturer's protocol. The TNF- $\alpha$ measurements were collected using a microplate reader at $450 \mathrm{~nm}$. The concentration of each sample was calculated from the standard curve.

2.8. Statistical Analyses. The data are presented as mean \pm SEM. GraphPad Prism version 5.0 (San Diego, CA, USA) for Windows was used to analyze the data. The one-way analyses of variance (ANOVAs) with Tukey's multiple comparison test were used to examine the differences between groups. A $P$ value below 0.05 was considered to be statistically significant.

\section{Results}

3.1. TMT Stimulated Intracellular ROS Generation in BV-2 Cells. BV-2 cells were incubated with various concentrations (300 nM-5 $\mu \mathrm{M}$ ) of TMT for $24 \mathrm{hr}$, and cell viabilities were then evaluated with MTT assays. As shown in Figure 1(a), $300 \mathrm{nM}-3 \mu \mathrm{M}$ TMT did not significantly affect cell viability. The cell viability was $92.9 \pm 5.1 \%$ at $3 \mu \mathrm{M}$ TMT, which was decreased to $81.1 \pm 2.7 \%$ at $5 \mu \mathrm{M}$ TMT compared with the control group. For further investigations, $3 \mu \mathrm{M}$ TMT was chosen to rule out the significant cell death induced by TMT.

We initially determined whether TMT could stimulate ROS production in BV-2 cells. Following the TMT exposure, the DCF fluorescence was quantified by flow cytometry at each indicated point in time. Increases in ROS generation were detected within $1 \mathrm{hr}$ of the TMT treatment (Figure 1(b)). A sustained increase in DCF-fluorescence was observed up to $6 \mathrm{hr}$ and reached 1.85-fold that of the control (Figure 1(b)). As NADPH oxidase is known to cause ROS production in macrophage [30, 31] and microglia [15, 28], we next examined whether NADPH oxidase might be involved in TMT-induced ROS generation in BV-2 cells. To inhibit the enzyme activity, $250 \mu \mathrm{M}$ of apocynin was applied $1 \mathrm{hr}$ prior to TMT treatment. Consequently, the intracellular ROS induced by TMT at $6 \mathrm{hr}$ was markedly diminished (Figure 1(c)). These data suggest that NADPH oxidase might play a crucial role in the production of oxidative stress in TMT-treated BV-2 cells.

3.2. TMT Activated $p 38$ and JNK MAPK in BV-2 Cells. We examined whether TMT could activate MAPK signaling cascades in BV-2 cells. The treated cells were then subjected to western blot analyses at each of the indicated time points. As shown in Figure 2, TMT led to significant increases in $\mathrm{p}$-JNK at 2, 4, and $6 \mathrm{hr}$ after TMT treatment. p-p38 also gradually increased from $4 \mathrm{hr}$ to $8 \mathrm{hr}$ of TMT treatment. However, the TMT-induced p-ERK exhibited transient changes throughout the time course and decreased at $8 \mathrm{hr}$ after TMT treatment.

3.3. TMT Exposure Activated NF- $\kappa B$ Signaling in BV-2 Cells. In activated microglia, NF- $\kappa \mathrm{B}$ signaling is considered to participate in inflammatory processes that result in the expression of inflammatory mediators, including iNOS and some cytokines, such as TNF- $\alpha$ and IL-1 $\beta$ [15]. However, it has not yet been reported whether TMT regulates NF- $\kappa \mathrm{B}$ activation in BV-2 cells. We further determined the alternations of NF- $\kappa \mathrm{B}$ signaling that followed exposure to TMT. Because $\mathrm{I} \kappa \mathrm{B} \alpha$ is known to be an inhibitory subunit of the NF$\kappa \mathrm{B}$ complex that prevents the nuclear translocation of $\mathrm{NF}-\kappa \mathrm{B}$, the expression levels of $\mathrm{I} \kappa \mathrm{B} \alpha$ and phospho- $\mathrm{I} \kappa \mathrm{B} \alpha$ protein were analyzed by western blot. Consequently, progressive trends of $\mathrm{I} \kappa \mathrm{B} \alpha$ degradation and $\mathrm{p}-\mathrm{I} \kappa \mathrm{B} \alpha$ elevation were detected over time (Figure 3). Typically, at 6 and $12 \mathrm{hr}$ after TMT treatment, $\mathrm{I} \kappa \mathrm{B} \alpha$ phosphorylation and the degradation of $\mathrm{I} \kappa \mathrm{B} \alpha$ were most apparent (Figure 3); these findings indicate that the TMT induced NF- $\kappa$ B activation in BV-2 cells.

3.4. p38 and JNK Activations Occur Earlier Than NF- $\kappa B$ Activation in TMT-Treated BV-2 Cells. Next, to examine the involvement of MAPKs on TMT-induced NF- $\kappa \mathrm{B}$ activation, SB203580 (p38 MAPK inhibitor), SP600125 (JNK MAPK inhibitor), and BAY11-7082 ( $\mathrm{\kappa} \kappa \mathrm{B} \alpha$ phosphorylation inhibitor) were applied prior to the TMT treatment. As shown in Figure 4(a), western blot analyses revealed that TMT significantly elevated $\mathrm{p}-\mathrm{I} \kappa \mathrm{B} \alpha$ expression and that its expression was suppressed by treatment with BAY11-7082. In the same experimental conditions, SB203580 and SP600125 also reduced the TMT-induced elevation of $\mathrm{p}-\mathrm{I} \kappa \mathrm{B} \alpha$. Furthermore, the translocation of the NF- $\kappa \mathrm{B}$ p 65 subunit into the nucleus was determined after $12 \mathrm{hr}$ of TMT treatment by immunofluorescence staining (Figure 4(b)). As shown in Figure 4(b), the NF- $\kappa \mathrm{B}$ p65 subunits were localized in the cytosol in the controls (Figure 4(b)-1); however, once the cells were stimulated with TMT, the subunits translocated 

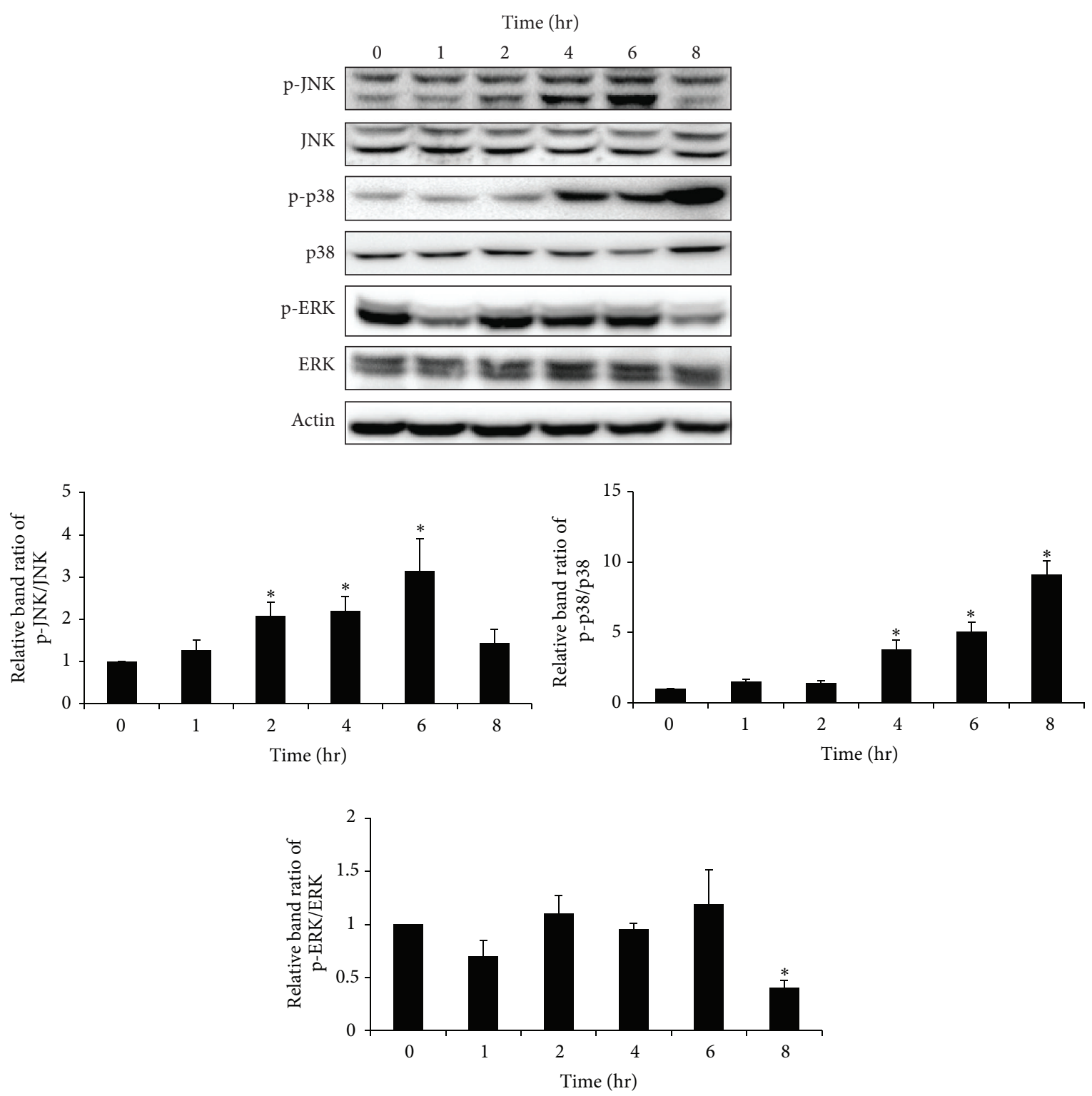

FIGURE 2: p38 and JNK were activated by TMT exposure in BV-2 cells. Treated cells were analyzed by western blot at each time period. The bar graphs represent the band intensity of each phosphoform of MAPKs normalized to total. The data are represented as mean \pm SEM $(n=5)$. ${ }^{*} P<0.05$ compared with the control group.

from the cytosol into the nucleus (Figure 4(b)-2). However, pretreatment with SB203580 (Figure 4(b)-3) or SP600125 (Figure 4(b)-4) inhibited the nuclear translocation of the NF$\kappa \mathrm{B}$ p65 subunits that was induced by TMT treatment. These data suggest that the activation of NF- $\kappa \mathrm{B}$ was regulated by MAPKs, particularly p38 and JNK, in TMT-treated BV-2 cells.

According to the data shown in Figure 4, upon TMT exposure, NF- $\kappa$ B activation by $\mathrm{p} 38$ and JNK was confirmed by comparing the alterations in $\mathrm{p}-\mathrm{I} \kappa \mathrm{B} \alpha$ and $\mathrm{NF}-\kappa \mathrm{B}$ p 65 nuclear translocation. The regulation of TMT-induced MAPK activation was then examined using BAY11-7082. Consequently, the levels of p-p38 and p-JNK were not affected by BAY117082, but each MAPK inhibitor (i.e., SB203580 and SP600125) markedly blocked its expression at $6 \mathrm{hr}$ after TMT treatment (Figures 5(a) and 5(b)). These data suggest that MAPK activation is upstream of the NF- $\kappa \mathrm{B}$ pathway. Together, these findings suggest that the TMT-induced p38 and JNK activations occurred prior to NF- $\kappa$ B activation in BV-2 cells.

3.5. TMT Induced Increases in iNOS Expression and the Production of NO and TNF- $\alpha$ in BV-2 Cells. The levels of some proinflammatory molecules, such as NO and TNF$\alpha$, were then examined in the culture media after the 

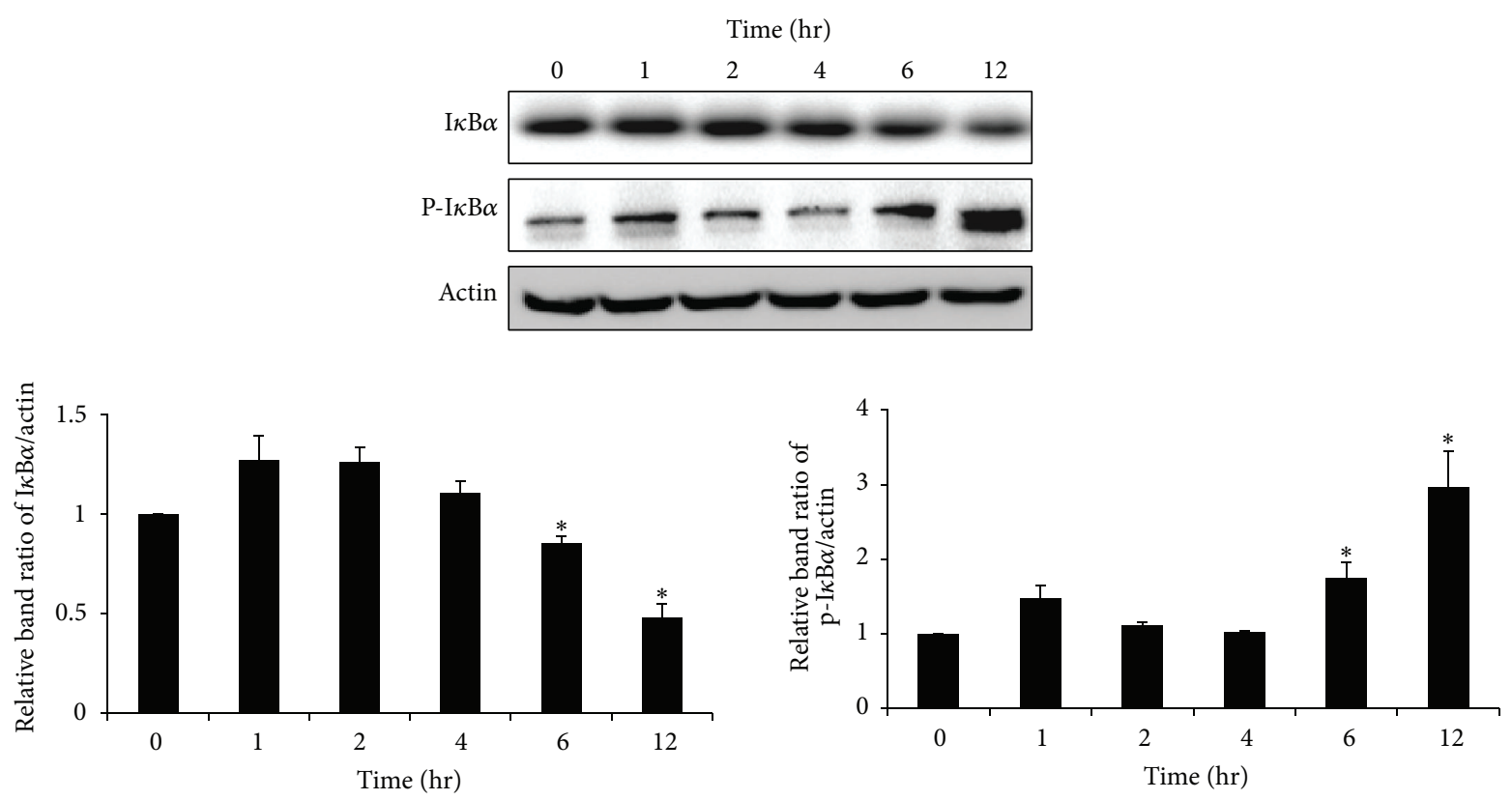

Figure 3: NF- $\kappa$ B signaling pathway was activated by TMT exposure in BV-2 cells. Treated cells were subjected to western blot analysis. The bar graphs represent the band intensity of each protein normalized to actin. The data are represented as mean \pm SEM $(n=5)$. ${ }^{*} P<0.05$ compared with the control group.

TMT treatments of BV-2 cells because these factors have been reported to participate with NF- $\kappa \mathrm{B}$ activation in the responses to various stimuli $[15,17]$. First, we examined iNOS expression at $12 \mathrm{hr}$ by western blot analysis (Figure 6(a)). TMT significantly increased iNOS expression by approximately 2.5-fold compared to the control; however, this effect was reversed by pretreatment with SB203580, SP600125, or BAY11-7082. Next, the amounts of released NO at $24 \mathrm{hr}$ were quantified using the Griess reagent method (Figure 6(b)). TMT treatment elevated NO production by approximately 6 -fold compared to that observed in the control (control; $0.28 \pm 0.16 \mu \mathrm{M}$, TMT; $1.67 \pm 0.18 \mu \mathrm{M}$ ). Pretreatment with SB203580 reduced the TMT-stimulated NO production by approximately $53 \%$, from $1.67 \pm 0.18 \mu \mathrm{M}$ to $0.79 \pm 0.24 \mu \mathrm{M}$. SP600125 and BAY11-7082 have also attenuated the TMTinduced NO level to $0.31 \pm 0.17 \mu \mathrm{M}$ and $0.58 \pm 0.29 \mu \mathrm{M}$, respectively. Moreover, TNF- $\alpha$ secretion from the treated BV2 cells was determined at $24 \mathrm{hr}$ in an ELISA. Continuous TNF- $\alpha$ secretion resulted from TMT-treatment and reached 53-fold the control level. However, the massive increase in TNF- $\alpha$ from TMT treatment was significantly reversed by pretreatment with SB203580, SP600125, or BAY11-7082 (Figure 6(c)).

3.6. CD11b Expression Was Increased in the TMT-Treated $B V-2$ Cells. CD11b and other microglial markers, including CD11a, CD11c, CD18, and others, have been reported to prominently appear in many neurodegenerative diseases [32]. Hence, we visualized the activated microglial cells with CD11b immunostaining at $12 \mathrm{hr}$ after TMT treatment. As shown in Figure 7-1, a faint cytoplasmic staining for CD11b can be observed in the control. Following TMT treatment (Figure 7-2), green fluorescence was detected more intensively compared to Figures 7-1, 7-3, and 7-4 and SB203580 and SP600125 prevented the elevation of CD11b expression that resulted from TMT treatment. These results support the notion that TMT elicited microglial activation by increasing CD11b surface molecules in BV-2 cells and that the p38 and JNK MAPK activations induced by TMT contributed to this increase in CD11b expression.

3.7. The NADPH Oxidase Inhibitor Apocynin Prevented the TMT-Induced Activations of MAPKs and NF- $\kappa B$ in the BV2 Cells. Our observations revealed that NADPH oxidasedependent ROS generation occurred in BV-2 cells and that treatment with apocynin remarkably suppressed the TMTinduced oxidative stress. Therefore, we further investigated the role of toxin-induced ROS generation in microglial activation. Importantly, reductions in NADPH oxidase activity mediated by apocynin treatment decreased TMT-induced pp38 and p-JNK at $6 \mathrm{hr}$ after TMT treatment (Figures 8(a) and $8(\mathrm{~b}))$. Apocynin also inhibited the downstream signal of TMT-induced MAPK activation and NF- $\kappa$ B activation, as shown by the western blot analyses of $\mathrm{p}-\mathrm{I} \kappa \mathrm{B} \alpha$ and iNOS at $12 \mathrm{hr}$ (Figures $8(\mathrm{c}$ ) and $8(\mathrm{~d})$ ), and consequently reduced TMT-induced NO (approximately 70\%) and TNF- $\alpha$ (approximately 94\%) after $24 \mathrm{hr}$ of TMT treatment (Figures 8(e) and $8(\mathrm{f})$ ). Thus, these data suggest that NADPH oxidase activity was the major source of TMT-induced ROS generation and 


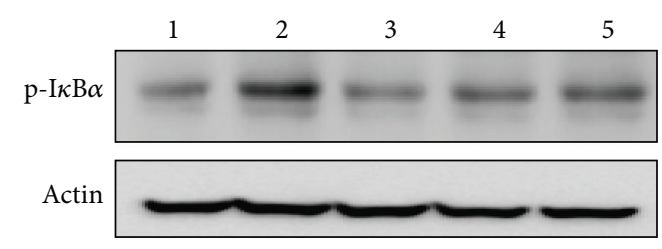
(1) Control
(4) $\mathrm{TMT}+\mathrm{SP} 600125$
(2) TMT
(5) $\mathrm{TMT}+\mathrm{BAY} 11-7082$
(3) $\mathrm{TMT}+\mathrm{SB} 203580$

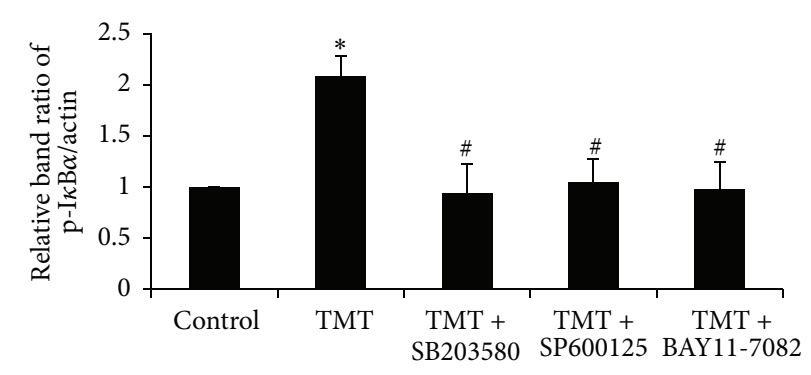

(a)
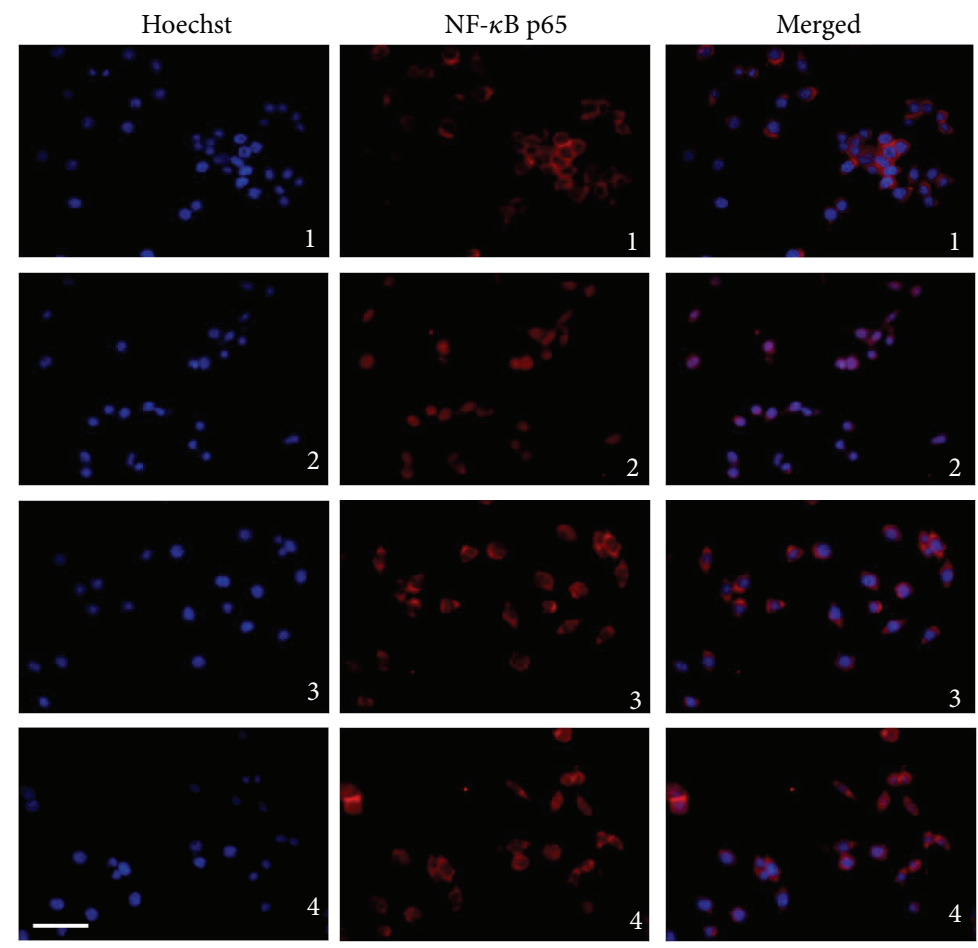
(1) Control
(3) $\mathrm{TMT}+\mathrm{SB} 203580$
(2) TMT
(4) $\mathrm{TMT}+\mathrm{SP} 600125$

(b)

FIGURE 4: TMT-induced NF- $\kappa$ B activation was reversed by p38 and JNK inhibitor in BV-2 cells. SB203580, SP600125, and BAY11-7082 were pretreated for $1 \mathrm{hr}$ and incubated with TMT for $12 \mathrm{hr}$. (a) Protein expression of phospho-I $\kappa \mathrm{B} \alpha$ was shown by western blot. The bar graph represents the band intensity of phosphoform normalized to actin. The data are represented as mean \pm SEM $(n=5)$. ${ }^{*} P<0.05$ compared with the control group. (b) Following the fixation of treated cells, immunocytochemistry method was carried to observe the translocation of NF- $\kappa$ B p 65 subunit morphologically. NF- $\kappa$ B p65 subunit was detected by red fluorescence (Alexa 568), nuclei were stained with blue fluorescence (Hoechst 33258), and the two different types of images were merged. The experiments were repeated more than 3 times. Scale bar: $20 \mu \mathrm{m}$. 


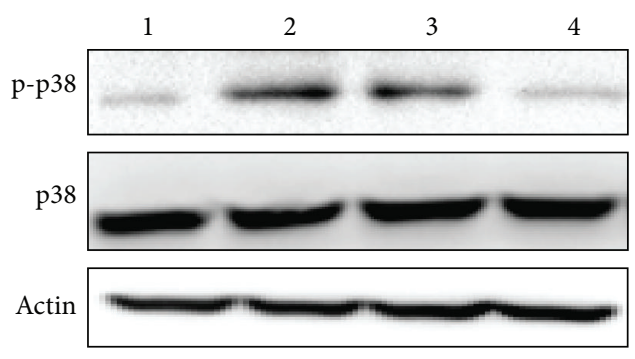

(1) Control

(2) TMT
(3) $\mathrm{TMT}+\mathrm{BAY} 11-7082$

(4) $\mathrm{TMT}+\mathrm{SB} 203580$

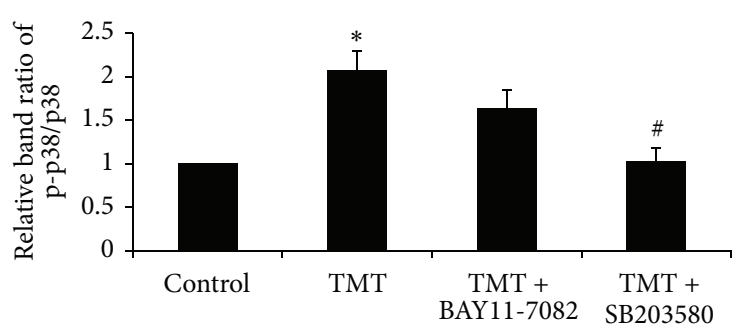

(a)

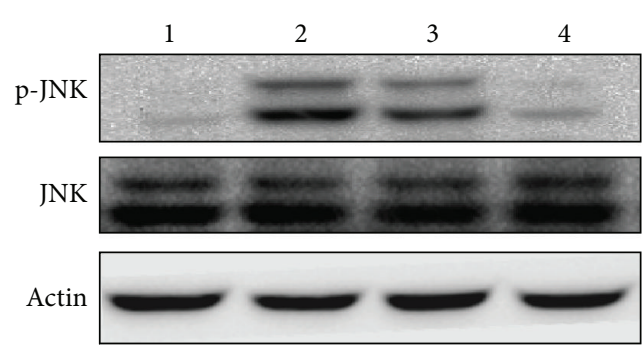

(1) Control

(3) $\mathrm{TMT}+\mathrm{BAY} 11-7082$

(2) TMT

(4) $\mathrm{TMT}+\mathrm{SP} 600125$

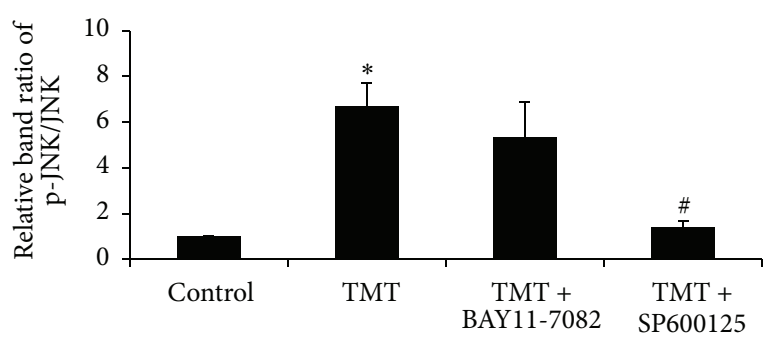

(b)

FIGURE 5: 338 and JNK phosphorylation were followed by NF- $\kappa$ B activation upon the TMT exposure in BV-2 cells. Treated cells were collected at $6 \mathrm{hr}$ and were subjected to western blot analysis. The bar graphs represent the band intensity of each phosphoform normalized to total. The data are represented as mean $\pm \operatorname{SEM}(n=5) .{ }^{*} P<0.05$ compared with the control group; ${ }^{\#} P<0.05$ compared with the value of TMT.

that intracellular ROS signaling is an upstream effector in BV2 microglial activation.

\section{Discussion}

Microglia are the innate immune cells of the CNS and play a crucial role in host defense against various invaders [15]. In response to various stimuli, microglia can be activated, which can include the following changes: (1) their morphologies can become ramified, amoeboid, or phagocytic [17, 24]; (2) expression of cell surface antigens, including CD11b, Iba-1, and OX-42 [18, 28]; and (3) production of bioactive factors, such as $\mathrm{NO}, \mathrm{O}_{2}{ }^{-}$, prostaglandins (PGs), TNF- $\alpha$, IL-1, IL12 , and IFN- $\gamma[15,17]$. In the present study, we initially determined whether TMT could directly activate BV- 2 cells. We observed increased production of NO, and TNF- $\alpha$ was detected as previously reported by other researchers $[5,6$, 24]. Additionally, we found the increased morphological appearance of CD11b in BV-2 cells with TMT treatment. The expression of CD11b, according to previous reports, is increased once microglial cells become activated by various stimuli although it can be detected in resting states [12, 18]. These findings indicated the direct activation of BV-2 cells by TMT exposure. However, some controversial results were previously reported that TMT either does not directly activate $[25,26]$ or partially activates microglia [8] with or without any significant morphological changes in microgliaenriched culture $[24,33]$. These different results have not been precisely explained yet. A few studies have documented that the discrepancies between in vitro studies using primary microglia-enriched cultures might have resulted from variations in the resting states of the microglia that depend on the cell isolation and culture maintenance conditions $[17,34,35]$. Furthermore, BV-2 cells are frequently used as a substitute for primary microglia. It has been reported that approximately $90 \%$ of the genes of mouse primary microglial and BV-2 cells overlap following LPS treatment and that this cell line is partially activated in resting states [11, 36]. Based on these reasons, it might be beneficial to analyze microglial activation more clearly during TMT toxicity via the use of BV-2 cells rather than other experimental models $[25,26]$.

To evaluate the underlying signaling pathways involved in the TMT-induced microglial activation, we performed investigations of the NF- $\kappa \mathrm{B}$ and MAPKs signaling pathways, which previously have been discussed in numerous studies as upstream effectors that target the production of inflammatory factors in microglia $[13,15]$. In the context of TMT, NF- $\kappa$ B activation has been reported in the murine hippocampus [37], human primary astrocytes [33], and a human neuroblastoma cell line [38]. However, TMT-induced NF- $\kappa \mathrm{B}$ activation in BV-2 cells has not been demonstrated yet. In our experiments, TMT-enhanced NF- $\kappa \mathrm{B}$ activity was observed and inhibiting the activity led to remarkable decreases in $\mathrm{NO}$ and TNF- $\alpha$ levels. It was partly comparable to the previous study that observed increased level of cytokines such as TNF$\alpha$, IL-1 $\beta$, and IL-6 [39]. Recently, it was also reported that dibutyltin, another organotin compound that causes severe 


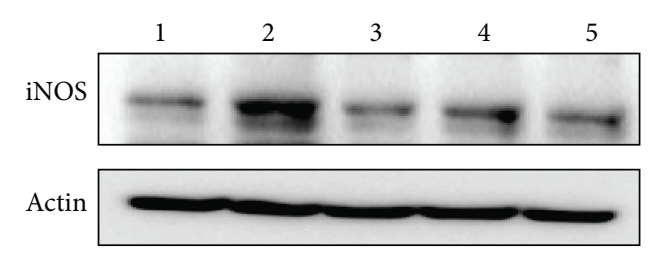
(1) Control
(4) $\mathrm{TMT}+\mathrm{SP} 600125$
(2) $\mathrm{TMT}$
(5) $\mathrm{TMT}+\mathrm{BAY} 11-7082$
(3) $\mathrm{TMT}+\mathrm{SB} 203580$

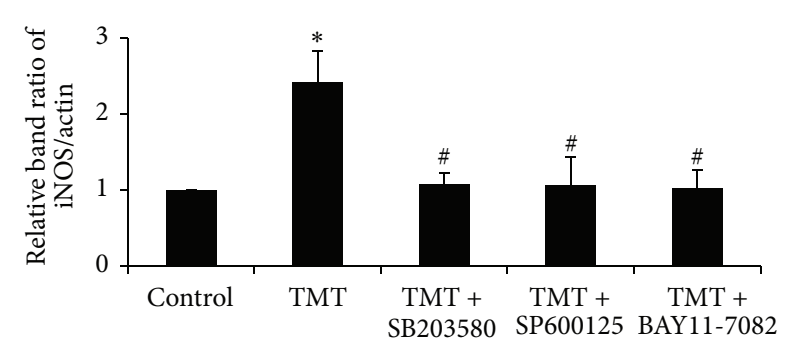

(a)

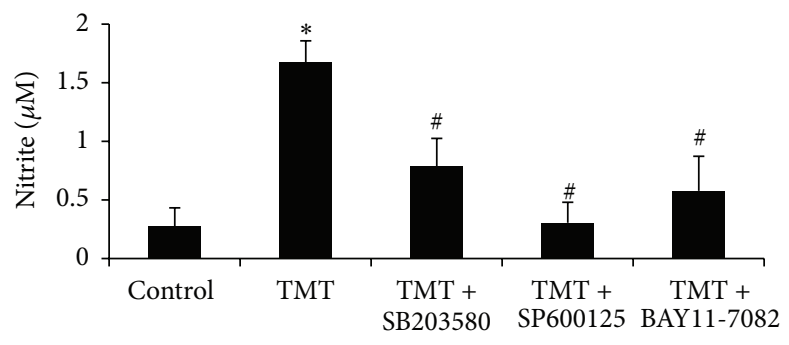

(b)

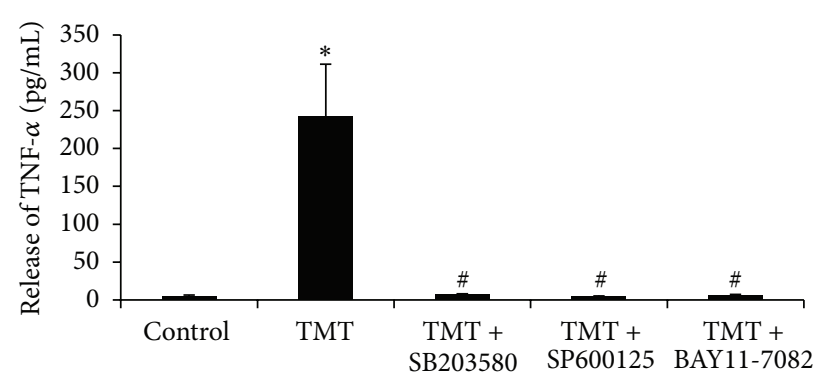

(c)

FIgURE 6: TMT increased iNOS expression and the production of NO and TNF- $\alpha$ in BV-2 cells. (a) At 12 hr, the expression of iNOS was analyzed by western blot. The bar graphs represent the band intensity of each protein normalized to actin. (b) At $24 \mathrm{hr}$, the culture media were taken to assess the level of NO by Griess method. (c) The culture media were also transferred into TNF- $\alpha$ Elisa kit to measure the level of TNF- $\alpha$ released from the treated cells. The concentration of TNF- $\alpha(\mathrm{pg} / \mathrm{mL})$ was measured by standard curve. The data are represented as mean \pm SEM $(n=5-7) .{ }^{*} P<0.05$ compared with the control group; ${ }^{\#} P<0.05$ compared with the value of TMT.

immunotoxicity and developmental toxicity in animals [40, $41]$, increased iNOS, TNF- $\alpha$, and IL-6 mRNA levels in BV-2 cells [42].

LPS [12] and many neurotoxins such as rotenone [16], A $\beta$ $[14,43]$ have been reported to stimulate BV-2 cells via MAPK activations that result in the modulation of inflammatory factors. Relying on previously reported information, we examined whether TMT could activate MAPKs in BV-2 cells. Therefore, p38 and JNK MAPK activations were resulted by TMT. Suppression of these MAPK activity reduced TMTinduced NF- $\kappa \mathrm{B}$ activation. In contrast, inhibition of NF- $\kappa \mathrm{B}$ activity did not affect on TMT-induced MAPK activations. Next, to elucidate the role of TMT-induced p38 and JNK activations on the production of inflammatory factors in BV2 cells, further experiments were performed, and remarkable suppressions of TMT-elevated iNOS, NO, and TNF- $\alpha$ levels resulted from pretreatment with SB203580, SP600125, or BAY11-7082. Similarly, decreased CD11b expression was observed following inhibition of MAPK activities. These results suggest that, following TMT exposure, MAPK activity occurs upstream of NF- $\kappa$ B activation in BV- 2 cells.

In the present study the ROS generation caused by TMT in BV-2 cells was initially examined because TMT-induced intracellular ROS generation has been frequently proposed to be involved in neurotoxicity $[7,44]$. The generation of ROS in microglia has been suggested to initiate various signaling pathways that are related to cytotoxic mechanisms, such as NF- $\kappa \mathrm{B}, \mathrm{MAPKs}$, and PI3K/AKT signaling cascades $[15,16]$. In our experiment, ROS generation was observed within $1 \mathrm{hr}$ of TMT treatment. Because the main route of ROS generation in microglia is known to be mediated through the activity of NADPH oxidase, which is localized on the surfaces of 

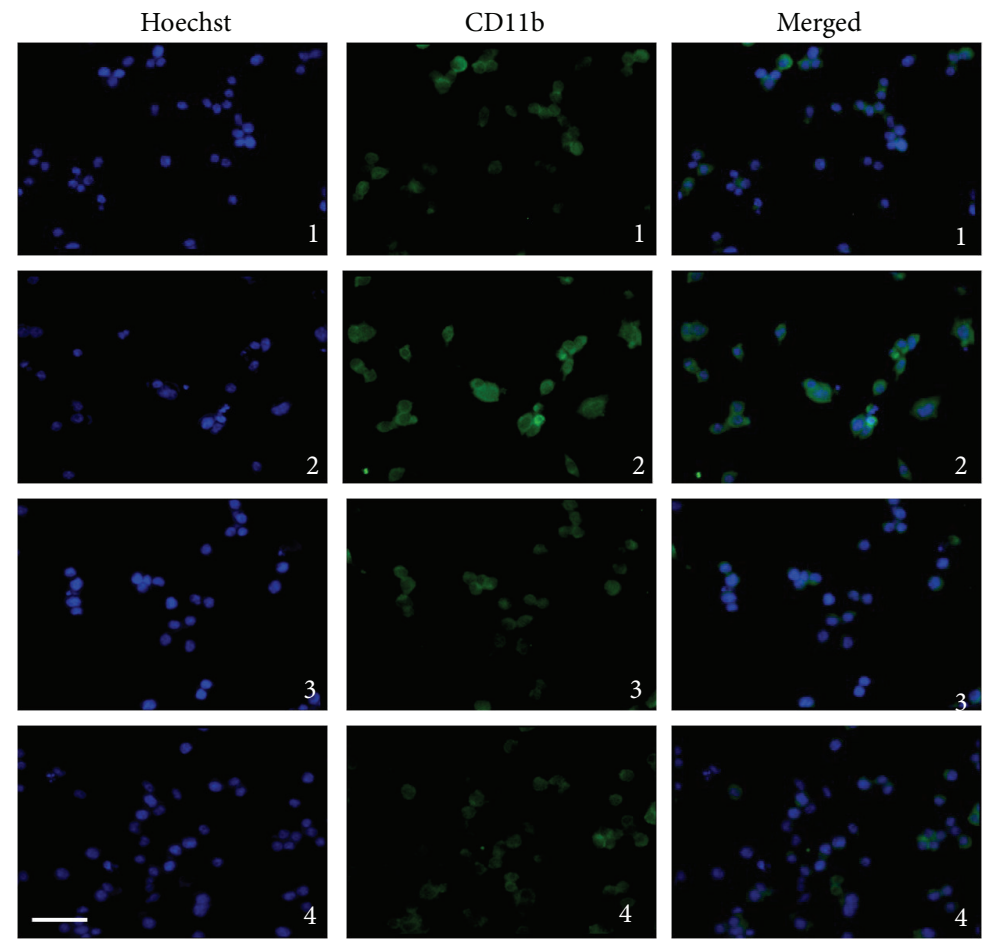
(1) Control
(3) $\mathrm{TMT}+\mathrm{SB} 203580$
(2) TMT
(4) $\mathrm{TMT}+\mathrm{SP} 600125$

Figure 7: TMT enhanced the expression of CD11b in BV-2 cells. The cells were treated and, after $12 \mathrm{hr}$, immunocytochemistry was carried to observe the change of CD11b expression among different groups. CD11b was detected by green fluorescence (Alexa 488) and nuclei were stained with blue fluorescence (Hoechst 33258). The two different types of images were merged. The experiments were repeated more than 3 times. Scale bar: $20 \mu \mathrm{m}$.

phagocytic cells and is upregulated in response to various stimuli $[15,28]$, we inhibited microglial NADPH oxidase with apocynin. Apocynin effectively reversed the elevation in the intracellular ROS induced by TMT. Our results are consistent with those of other reports that have illustrated the involvement of NADPH oxidase in ROS generation in response to multiple stimuli in phagocytic cells $[15,28$, 30]. We further determined the relationship of NADPH oxidase-dependent ROS generation with signaling pathway on TMT-induced microglial activation. Interestingly, in addition to the reduction in ROS formation, apocynin prevented the influence of TMT on all parameters, including TMTincreased phosphorylation of $\mathrm{p} 38$, JNK and $\mathrm{I} \kappa \mathrm{B} \alpha$, iNOS expression, and $\mathrm{NO}$ and TNF- $\alpha$ production. Hence, these findings indicate that TMT-induced MAPKs and NF- $\kappa \mathrm{B}$ are targeted by intracellular ROS generation in BV-2 cells. The mechanisms involved in regulation of NADPH oxidase have not been evaluated in this study. However, the involvement of PKC in phagocyte NADPH oxidase activation was reported [45]. There are some reports showing that TMT-increased intracellular calcium results in rat hippocampal neurons [46] and TMT-activated PKC leads to cytotoxicity in PC12 cells [47]. From these studies, it can be suggested that PKC and intracellular calcium might be involved in NADPH oxidase activation in TMT-treated BV-2 cells.

\section{Conclusions}

Our results showed that TMT-induced oxidative stress mediated p38 and JNK phosphorylation and NF- $\kappa \mathrm{B}$ activation resulting in NO and TNF- $\alpha$ production in BV- 2 cells. But, all of these TMT-induced effects were reversed by the inhibition of NADPH oxidase activity. These results indicate that TMT could directly activate microglial cell via NADPH oxidasedependent ROS generation. To our knowledge, this is the first report that reveals the direct impact of TMT on BV-2 microglial cells related to underlying mechanisms sequentially (Figure 9). Taken together, it can be suggested that generated ROS and proinflammatory factors from microglia might be involved in TMT-induced neuronal cell death.

\section{Conflict of Interests}

The authors declare that there is no conflict of interests regarding the publication of this paper. 


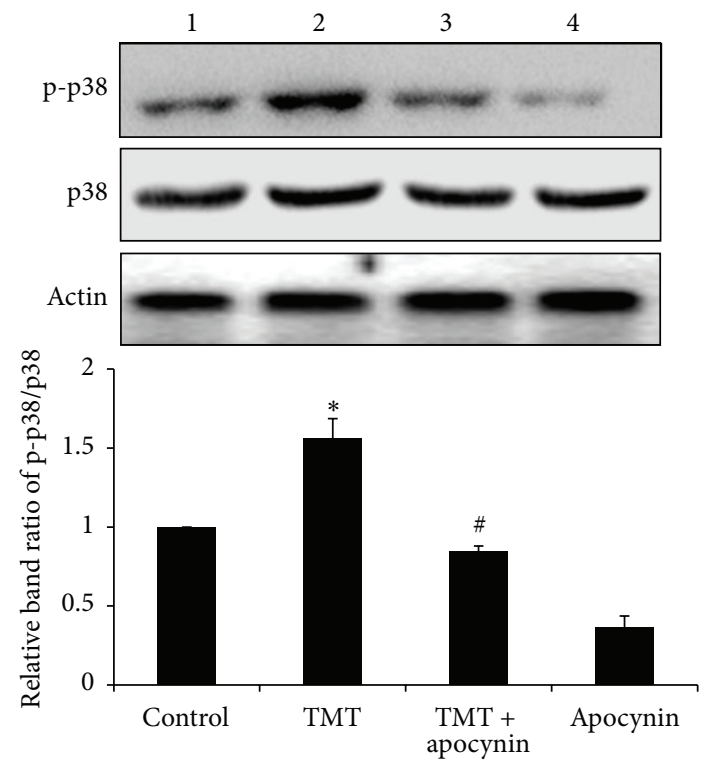

(a)
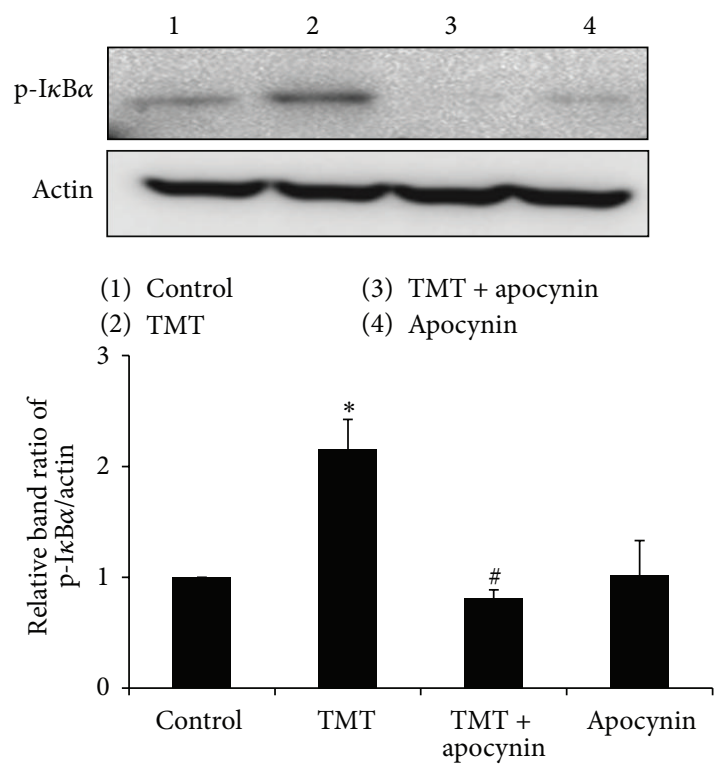

(c)

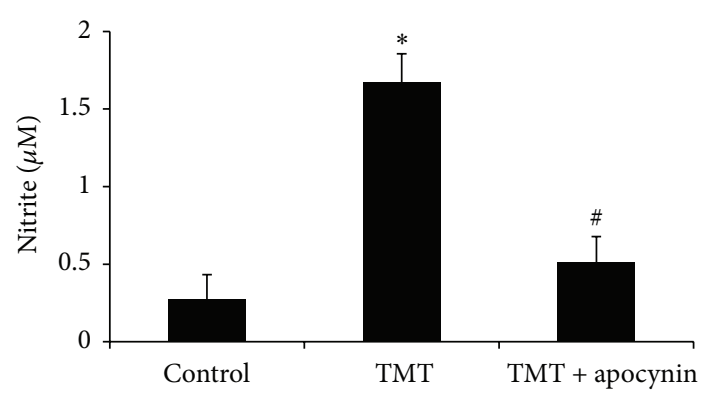

(e)

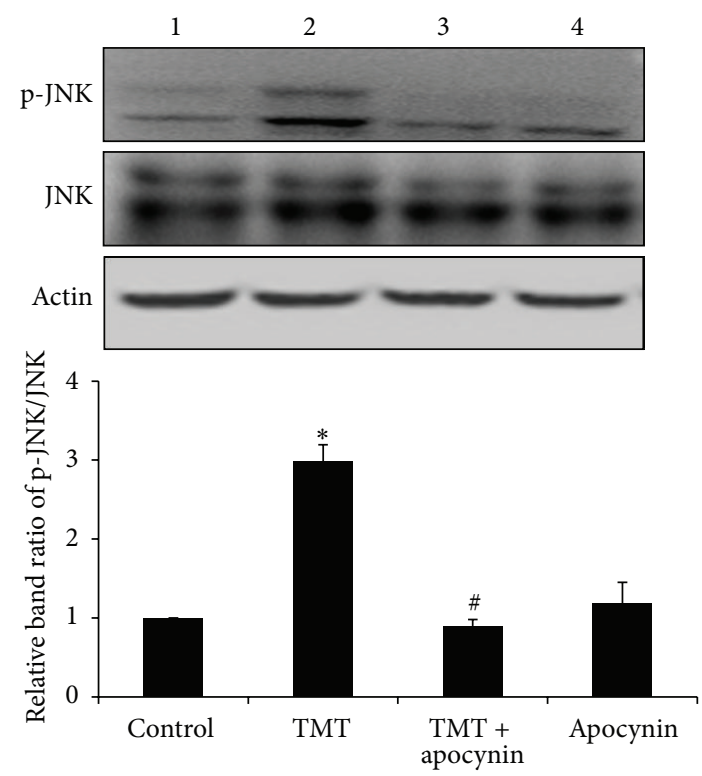

(b)

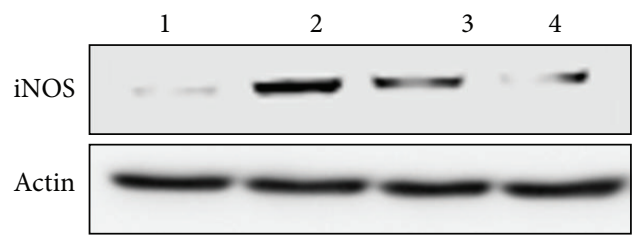

(1) Control

(2) TMT

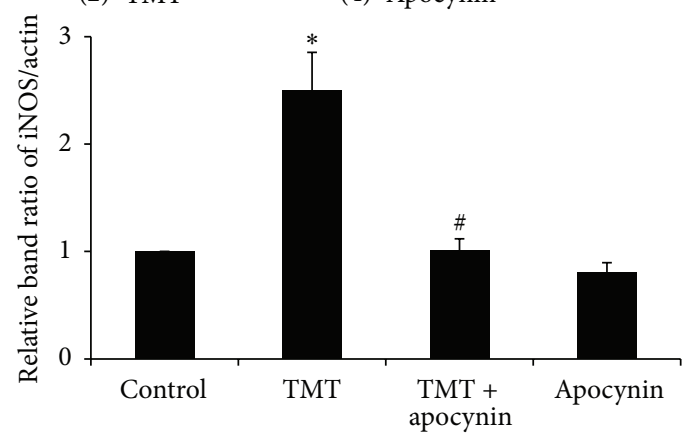

(3) TMT + apocynin

(4) Apocynin

(d)

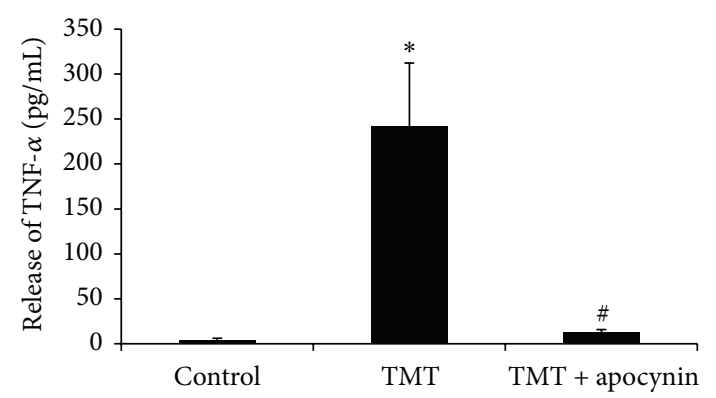

(f)

FIGURE 8: Apocynin suppressed TMT-induced MAPKs activations, p-IKB, iNOS, NO production, and TNF- $\alpha$ release in BV-2 cells. (a)-(d) The treated cells were subjected to western blot analysis to assess the expression of phosphorylated p38 and JNK at $6 \mathrm{hr}$ and p-I $\kappa \mathrm{B} \alpha$ and iNOS at $12 \mathrm{hr}$. The bar graphs represent the band intensity of each protein form normalized to total. For (e) and (f), the culture media of treated cells at $24 \mathrm{hr}$ were collected and used for (e) NO production measurement by Griess reagent method and (f) TNF- $\alpha$ detection by using Elisa kit. The data are represented as mean \pm SEM $(n=4-7){ }^{*} P<0.05$ compared with the control group; ${ }^{*} P<0.05$ compared with the value of TMT. 


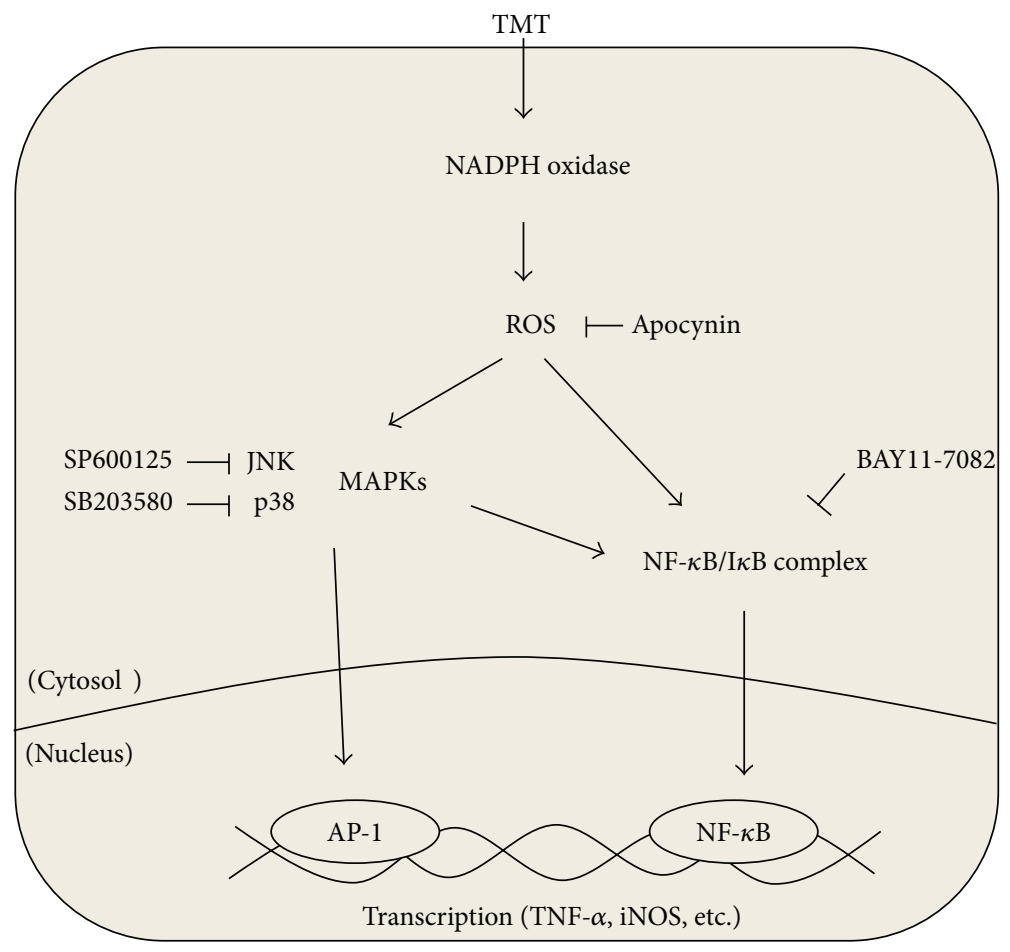

FIGURE 9: Schematic diagram depicting the possible signaling pathway induced by TMT in BV-2 cells. TMT-induced intracellular ROS may be dominantly generated via NADPH oxidase in BV-2 cells. ROS are then able to activate MAPKs and NF- $\kappa$ B resulting in enhanced production of NO and TNF- $\alpha$. In this experiment, p38 and JNK MAPK activations occurred earlier than NF- $\kappa$ B, and pretreatment with SB203580 or SP600125 suppressed TMT-induced NF- $\kappa$ B activation. Although the mechanism of MAPK regulation in NF- $\kappa$ B activation is not entirely clear, MAPKs may target various protein kinases relating to NF- $\kappa \mathrm{B}$ activation and/or transactivation at NF- $\kappa \mathrm{B}$ transcriptional level.

\section{Acknowledgment}

This work was supported by the Education and Research Encouragement Fund of Seoul National University Hospital (2015).

\section{References}

[1] K. Furuhashi, M. Ogawa, Y. Suzuki, Y. Endo, Y. Kim, and G. Ichihara, "Methylation of dimethyltin in mice and rats," Chemical Research in Toxicology, vol. 21, no. 2, pp. 467-471, 2008.

[2] X. Tang, N. Li, L. Kang et al., "Chronic low level trimethyltin exposure and the risk of developing nephrolithiasis," Осcupational \& Environmental Medicine, vol. 70, no. 8, pp. 561-567, 2013.

[3] C. I. Yoo, Y. Kim, K. S. Jeong et al., "A case of acute organotin poisoning," Journal of Occupational Health, vol. 49, no. 4, pp. 305-310, 2007.

[4] M. C. Geloso, V. Corvino, and F. Michetti, "Trimethyltininduced hippocampal degeneration as a tool to investigate neurodegenerative processes," Neurochemistry International, vol. 58, no. 7, pp. 729-738, 2011.

[5] C. A. McPherson, A. D. Kraft, and G. J. Harry, "Injury-induced neurogenesis: consideration of resident microglia as supportive of neural progenitor cells," Neurotoxicity Research, vol. 19, no. 2, pp. 341-352, 2011.
[6] J. Noraberg, J. B. P. Gramsbergen, F. Fonnum, and J. Zimmer, "Trimethyltin (TMT) neurotoxicity in organotypic rat hippocampal slice cultures," Brain Research, vol. 783, no. 2, pp. 305-315, 1998.

[7] P. Gunasekar, L. Li, K. Prabhakaran, V. Eybl, J. L. Borowitz, and G. E. Isom, "Mechanisms of the apoptotic and necrotic actions of trimethyltin in cerebellar granule cells," Toxicological Sciences, vol. 64, no. 1, pp. 83-89, 2001.

[8] B. Viviani, E. Corsini, C. L. Galli, and M. Marinovich, "Glia increase degeneration of hippocampal neurons through release of tumor necrosis factor-alpha," Toxicology and Applied Pharmacology, vol. 150, no. 2, pp. 271-276, 1998.

[9] C. Nilsberth, B. Kostyszyn, and J. Luthman, "Changes in APP, PS1 and other factors related to Alzheimer's disease pathophysiology after trimethyltin-induced brain lesion in the rat," Neurotoxicity Research, vol. 4, no. 7-8, pp. 625-636, 2002.

[10] L. Minghetti, M. A. Ajmone-Cat, M. A. De Berardinis, and R. De Simone, "Microglial activation in chronic neurodegenerative diseases: roles of apoptotic neurons and chronic stimulation," Brain Research Reviews, vol. 48, no. 2, pp. 251-256, 2005.

[11] A. Henn, S. Lund, M. Hedtjärn, A. Schrattenholz, P. Pörzgen, and M. Leist, "The suitability of BV2 cells as alternative model system for primary microglia cultures or for animal experiments examining brain inflammation," Altex, vol. 26, no. 2, pp. 83-94, 2009.

[12] D. Liu, Z. Wang, S. Liu, F. Wang, S. Zhao, and A. Hao, "Antiinflammatory effects of fluoxetine in lipopolysaccharide(LPS)stimulated microglial cells," Neuropharmacology, vol. 61, no. 4, pp. 592-599, 2011. 
[13] F. Q. He, B. Y. Qiu, T. K. Li et al., "Tetrandrine suppresses amyloid- $\beta$-induced inflammatory cytokines by inhibiting NF$\kappa \mathrm{B}$ pathway in murine BV2 microglial cells," International Immunopharmacology, vol. 11, no. 9, pp. 1220-1225, 2011.

[14] A. D. Bachstetter, B. Xing, L. de Almeida, E. R. Dimayuga, D. M. Watterson, and L. J. van Eldik, "Microglial p38 $\alpha$ MAPK is a key regulator of proinflammatory cytokine up-regulation induced by toll-like receptor (TLR) ligands or beta-amyloid (A $\beta)$," Journal of Neuroinflammation, vol. 8, article 79, 2011.

[15] M. E. Lull and M. L. Block, "Microglial activation and chronic neurodegeneration," Neurotherapeutics, vol. 7, no. 4, pp. 354365,2010

[16] F. Gao, D. Chen, Q. Hu, and G. Wang, "Rotenone directly induces BV2 cell activation via the p38 MAPK pathway," PLoS ONE, vol. 8, no. 8, Article ID e72046, 2013.

[17] R. M. Ransohoff and V. H. Perry, "Microglial physiology: unique stimuli, specialized responses," Annual Review of Immunology, vol. 27, pp. 119-145, 2009.

[18] S. Wakselman, C. Béchade, A. Roumier, D. Bernard, A. Triller, and A. Bessis, "Developmental neuronal death in hippocampus requires the microglial CD11b integrin and DAP12 immunoreceptor," Journal of Neuroscience, vol. 28, no. 32, pp. 8138-8143, 2008.

[19] S. Y. Park, M. L. Jin, Y. H. Kim, Y. Kim, and S. J. Lee, "Antiinflammatory effects of aromatic-turmerone through blocking of NF- $\kappa$ B, JNK, and p38 MAPK signaling pathways in amyloid $\beta$-stimulated microglia," International Immunopharmacology, vol. 14, no. 1, pp. 13-20, 2012.

[20] L. J. Peterson and P. M. Flood, "Oxidative stress and microglial cells in Parkinson's disease," Mediators of Inflammation, vol. 2012, Article ID 401264, 12 pages, 2012.

[21] H. Akiyama, S. Barger, S. Barnum et al., "Inflammation and Alzheimer's disease," Neurobiology of Aging, vol. 21, no. 3, pp. 383-421, 2000.

[22] C. L. D'Hellencourt and G. J. Harry, "Molecular profiles of mRNA levels in laser capture microdissected murine hippocampal regions differentially responsive to TMT-induced cell death," Journal of Neurochemistry, vol. 93, no. 1, pp. 206-220, 2005.

[23] I. Figiel and K. Dzwonek, "TNF $\alpha$ and TNF receptor 1 expression in the mixed neuronal-glial cultures of hippocampal dentate gyrus exposed to glutamate or trimethyltin," Brain Research, vol. 1131, no. 1, pp. 17-28, 2007.

[24] C. Eskes, L. Juillerat-Jeanneret, G. Leuba, and P. Honegger, "Involvement of microglia-neuron interactions in the tumor necrosis factor- $\alpha$ release, microglial activation, and neurodegeneration induced by trimethyltin," Journal of Neuroscience Research, vol. 71, no. 4, pp. 583-590, 2003.

[25] C. Röhl and J. Sievers, "Microglia is activated by astrocytes in trimethyltin intoxication," Toxicology and Applied Pharmacology, vol. 204, no. 1, pp. 36-45, 2005.

[26] C. Röhl, M. Grell, and E. Maser, “The organotin compounds trimethyltin (TMT) and triethyltin (TET) but not tributyltin (TBT) induce activation of microglia co-cultivated with astrocytes," Toxicology in Vitro, vol. 23, no. 8, pp. 1541-1547, 2009.

[27] E. Blasi, R. Barluzzi, V. Bocchini, R. Mazzolla, and F. Bistoni, "Immortalization of murine microglial cells by a v-raf/v-myc carrying retrovirus," Journal of Neuroimmunology, vol. 27, no. 2-3, pp. 229-237, 1990.

[28] L. Yan, S. Liu, C. Wang et al., "JNK and NADPH oxidase involved in fluoride-induced oxidative stress in BV-2 microglia cells," Mediators of Inflammation, vol. 2013, Article ID 895975, 10 pages, 2013.

[29] H. Wilms, J. Claasen, C. Röhl, J. Sievers, G. Deuschl, and R. Lucius, "Involvement of benzodiazepine receptors in neuroinflammatory and neurodegenerative diseases: evidence from activated microglial cells in vitro," Neurobiology of Disease, vol. 14, no. 3, pp. 417-424, 2003.

[30] Y. S. Bae, J. H. Lee, S. H. Choi et al., "Macrophages generate reactive oxygen species in response to minimally oxidized lowdensity lipoprotein: toll-like receptor 4 - and spleen tyrosine kinase-dependent activation of NADPH oxidase 2," Circulation Research, vol. 104, no. 2, pp. 210-218, 2009.

[31] W. Liu, Y. Peng, Y. Yin, Z. Zhou, W. Zhou, and Y. Dai, “The involvement of NADPH oxidase-mediated ROS in cytokine secretion from macrophages induced by Mycobacterium tuberculosis ESAT-6," Inflammation, vol. 37, no. 3, pp. 880-892, 2014.

[32] A. Roy, Y. K. Fung, X. Liu, and K. Pahan, "Up-regulation of microglial CD11b expression by nitric oxide," The Journal of Biological Chemistry, vol. 281, no. 21, pp. 14971-14980, 2006.

[33] C. Reali, F. Scintu, R. Pillai, R. Donato, F. Michetti, and V. Sogos, "S100B counteracts effects of the neurotoxicant trimethyltin on astrocytes and microglia," Journal of Neuroscience Research, vol. 81, no. 5, pp. 677-686, 2005.

[34] F. L. Heppner, K. Roth, R. Nitsch, and N. P. Hailer, "Vitamin $\mathrm{E}$ induces ramification and downregulation of adhesion molecules in cultured microglial cells," Glia, vol. 22, no. 2, pp. 180-188, 1998.

[35] C. Caldeira, A. F. Oliveira, C. Cunha et al., "Microglia change from a reactive to an age-like phenotype with the time in culture," Frontiers in Cellular Neuroscience, vol. 8, article 152, 2014.

[36] B. Stansley, J. Post, and K. Hensley, "A comparative review of cell culture systems for the study of microglial biology in Alzheimer's disease," Journal of Neuroinflammation, vol. 9, article 115, 2012.

[37] C. A. Kassed, T. L. Butler, G. W. Patton et al., "Injury-induced NF-kappaB activation in the hippocampus: implications for neuronal survival," The FASEB Journal, vol. 18, no. 6, pp. 723$724,2004$.

[38] Y. Qing, Y. Liang, Q. Du et al., "Apoptosis induced by Trimethyltin chloride in human neuroblastoma cells SY5Y is regulated by a balance and cross-talk between NF- $\kappa \mathrm{B}$ and MAPKs signaling pathways," Archives of Toxicology, vol. 87, no. 7, pp. 1273-1285, 2013.

[39] J. Kim, M. Yang, and Y. Son, "Glial activation with concurrent up-regulation of inflammatory mediators in trimethyltininduced neurotoxicity in mice," Acta Histochemica, vol. 116, no. 8, pp. 1490-1500, 2014.

[40] S. M. Jenkins, K. Ehman, and S. Barone Jr., "Structure-activity comparison of organotin species: dibutyltin is a developmental neurotoxicant in vitro and in vivo," Developmental Brain Research, vol. 151, no. 1-2, pp. 1-12, 2004.

[41] M. Ema, A. Arima, K. Fukunishi et al., "Developmental toxicity of dibutyltin dichloride given on three consecutive days during organogenesis in cynomolgus monkeys," Drug and Chemical Toxicology, vol. 32, no. 2, pp. 150-157, 2009.

[42] B. Chantong, D. V. Kratschmar, A. Lister, and A. Odermatt, "Dibutyltin promotes oxidative stress and increases inflammatory mediators in BV-2 microglia cells," Toxicology Letters, vol. 230, no. 2, pp. 177-187, 2014.

[43] B. Xing, A. D. Bachstetter, and L. J. van Eldik, "Microglial p38 $\alpha$ MAPK is critical for LPS-induced neuron degeneration, 
through a mechanism involving TNF $\alpha$," Molecular Neurodegeneration, vol. 6, no. 1, article 84, 2011.

[44] S. M. Jenkins and S. Barone Jr., "The neurotoxicant trimethyltin induces apoptosis via caspase activation, p38 protein kinase, and oxidative stress in PC12 cells," Toxicology Letters, vol. 147, no. 1, pp. 63-72, 2004.

[45] H. Raad, M.-H. Paclet, T. Boussetta et al., "Regulation of the phagocyte NADPH oxidase activity: phosphorylation of gp91phox/NOX2 by protein kinase $\mathrm{C}$ enhances its diaphorase activity and binding to Rac2, p67phox, and p47phox," The FASEB Journal, vol. 23, no. 4, pp. 1011-1022, 2009.

[46] R. Piacentini, C. Gangitano, S. Ceccariglia et al., "Dysregulation of intracellular calcium homeostasis is responsible for neuronal death in an experimental model of selective hippocampal degeneration induced by trimethyltin," Journal of Neurochemistry, vol. 105, no. 6, pp. 2109-2121, 2008.

[47] M. D. Kane, C.-W. Yang, P. G. Gunasekar, and G. E. Isom, "Trimethyltin stimulates protein kinase $\mathrm{C}$ translocation through receptor-mediated phospholipase $\mathrm{C}$ activation in PC12 cells," Journal of Neurochemistry, vol. 70, no. 2, pp. 509-514, 1998. 


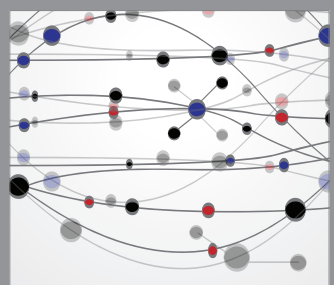

The Scientific World Journal
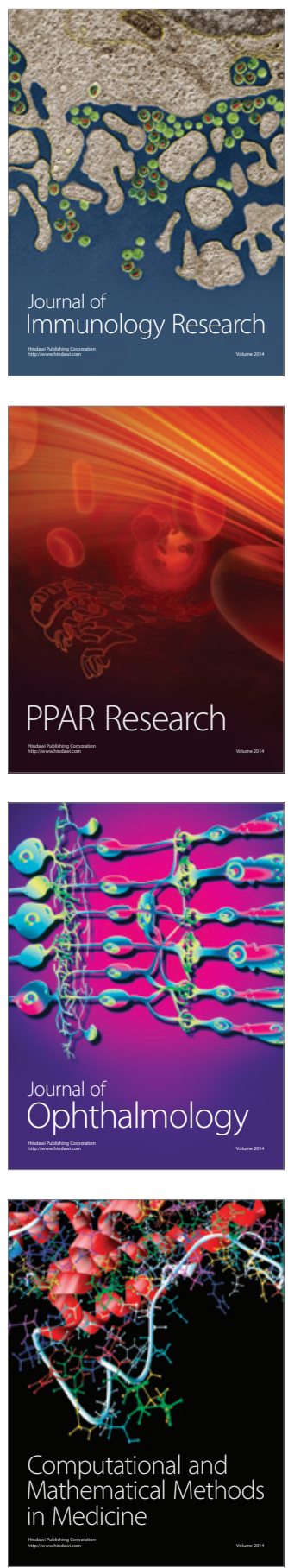

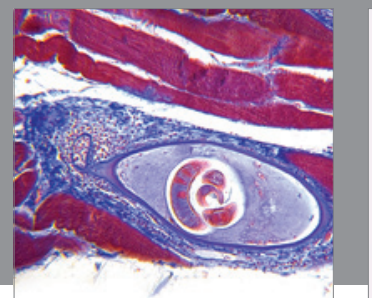

Gastroenterology

Research and Practice
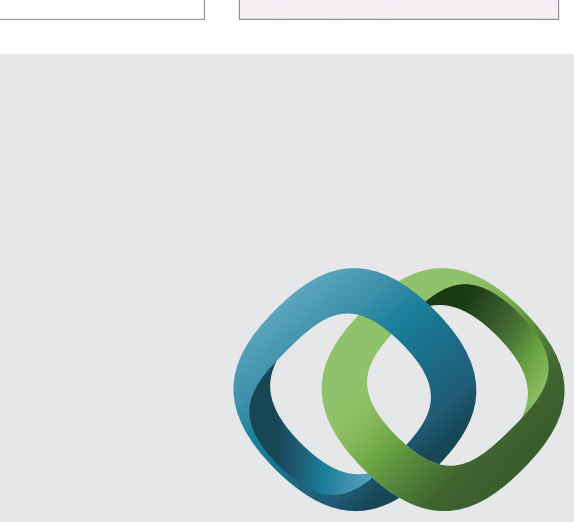

\section{Hindawi}

Submit your manuscripts at

http://www.hindawi.com
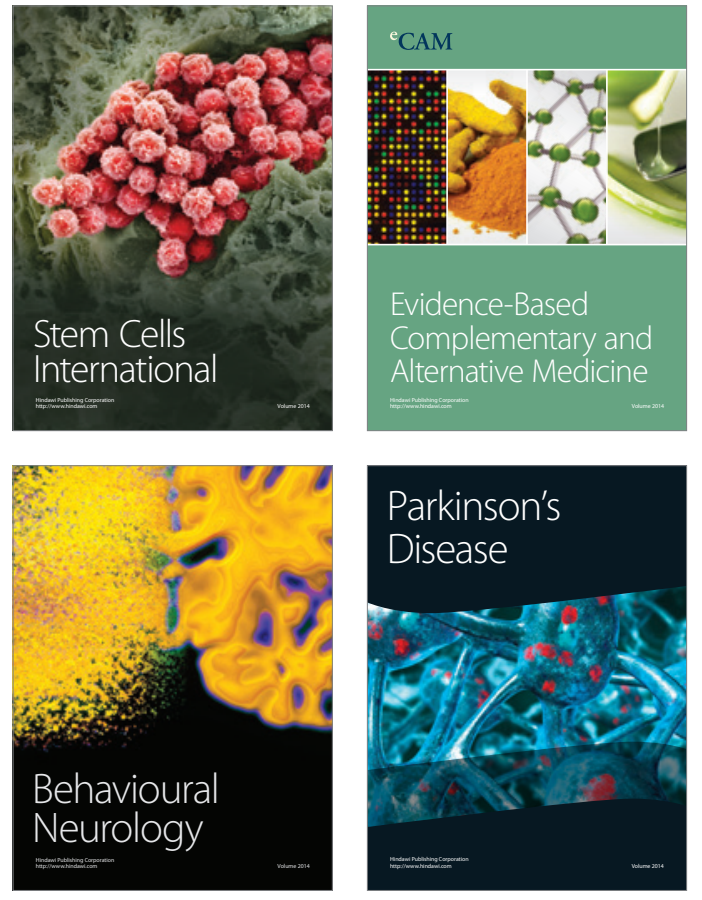
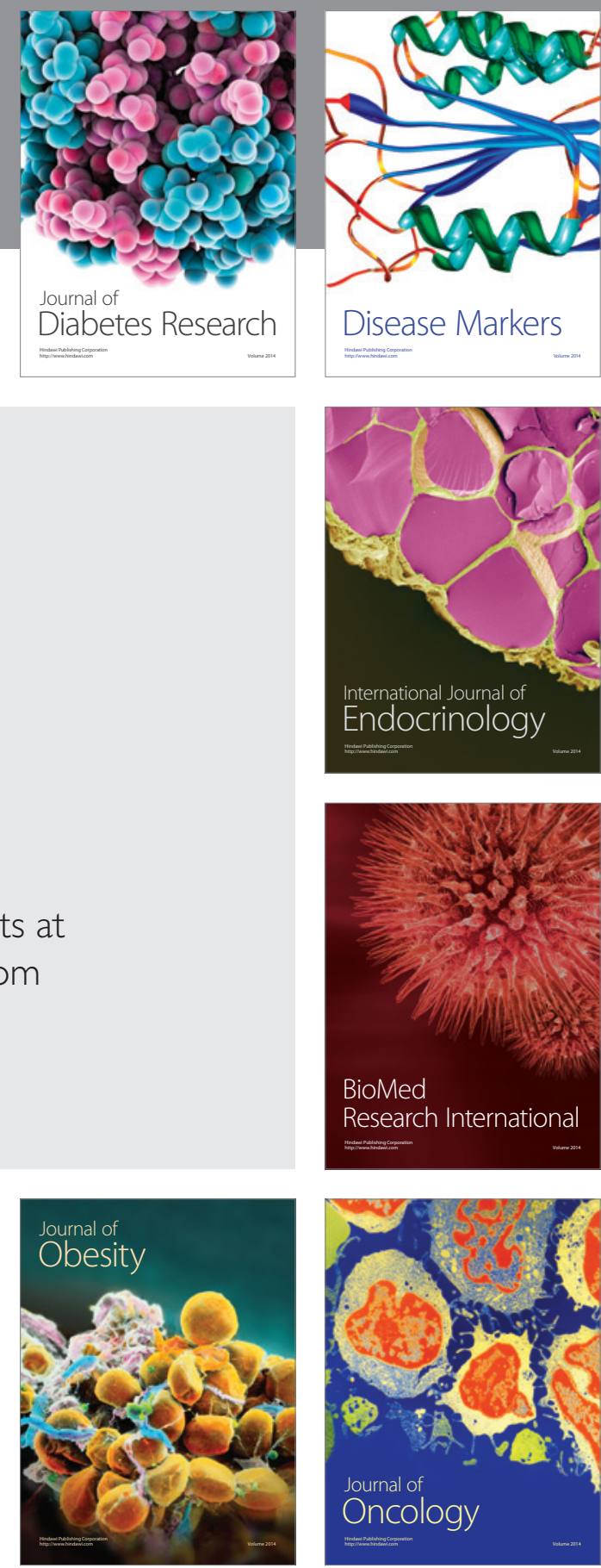

Disease Markers
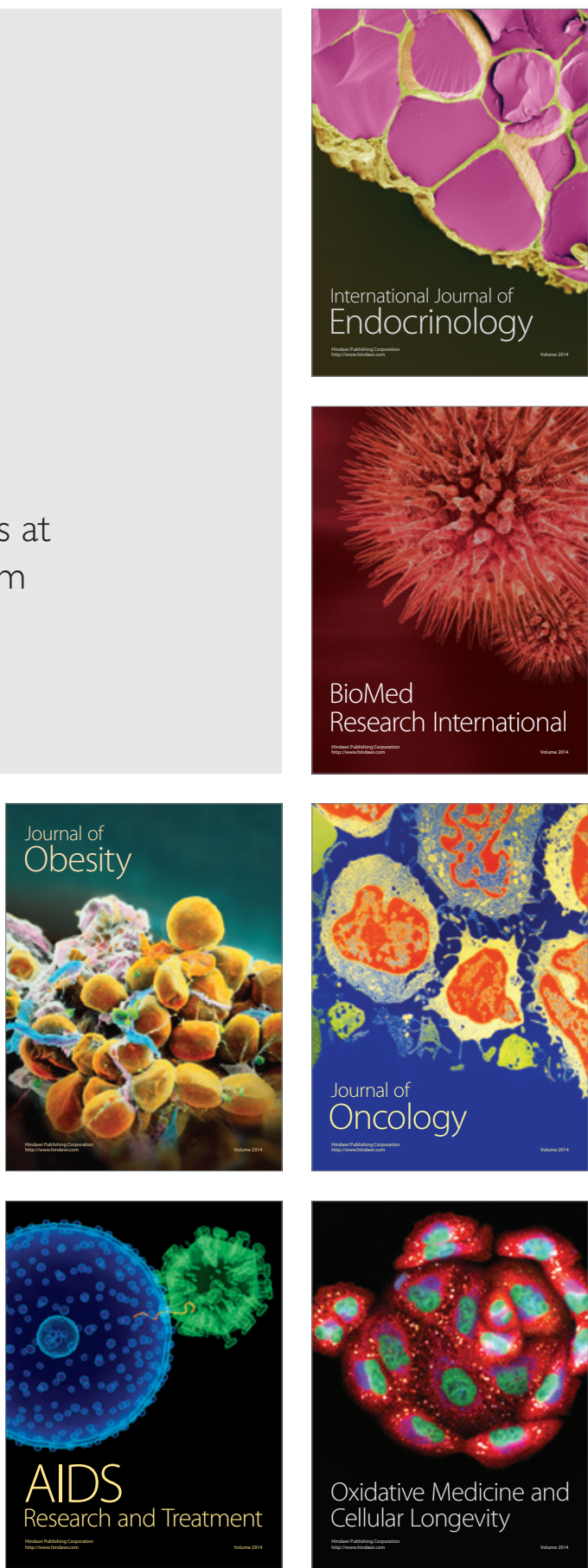